Rita Franco Rêgo a

(iD) https://orcid.org/0000-0002-0632-4546

Juliana dos Santos Müiller ${ }^{\mathrm{a}, \mathrm{b}, \mathrm{c}}$

(iD) https://orcid.org/0000-0002-8593-304X

Ila Rocha Falcão ${ }^{\mathrm{a}, \mathrm{d}}$

(iD) https://orcid.org/0000-0001-6961-3858

Paulo Gilvane Lopes Pena ${ }^{\mathrm{a}}$

(iD https://orcid.org/0000-0001-9653-5509

\section{Vigilância em saúde do trabalhador da pesca artesanal na Baía de Todos os Santos: da invisibilidade à proposição de políticas públicas para o Sistema Único de Saúde (SUS)}

\author{
Occupational health surveillance of artisanal fishermen in the \\ Baía de Todos os Santos: from invisibility to the proposal of \\ public policies for the Unified Health System (SUS)
}

a Universidade Federal da Bahia, Programa de Pós-Graduação em Saúde, Ambiente e Trabalho, Faculdade de Medicina da Bahia. Salvador, BA, Brasil.

bInstituto Federal de Educação, Ciência e Tecnologia da Bahia, Departamento de Tecnologia em Saúde e Biologia. Salvador, BA, Brasil.

'Universidade Federal da Bahia, Programa de Pós-Graduação em Processos Interativos de Órgãos e Sistemas. Instituto de Ciências da Saúde ,Salvador, BA, Brasil.

d Universidade Federal da Bahia, Programa de Pós-Graduação em Alimentos, Nutrição e Saúde. Salvador, BA, Brasil.

Contato:

Rita Franco Rêgo

E-mail:

ritarego@ufba.br

O trabalho foi financiado pelo Conselho Nacional de Desenvolvimento Científico e Tecnológico (CNPq), processo $n^{\circ}$ 203056/2014-0.

Os autores declaram que não há conflitos de interesses.

Os autores informam que o trabalho não foi baseado em tese e não foi apresentado em eventos científicos.
Recebido: 01/02/18

Revisado: 04/05/18

Aceito: $13 / 06 / 18$

\section{Resumo}

Introdução: pescadores são uma das maiores e mais tradicionais categorias de trabalhadores no mundo. Para reduzir lacunas do conhecimento sobre os problemas de saúde relacionados a essa atividade e desenvolver ações com o Sistema Único de Saúde (SUS), em 2006 foram iniciados estudos e ações dirigidos aos trabalhadores da pesca artesanal e mariscagem, envolvendo 13 municípios, na Baía de Todos os Santos, nos estado da Bahia. Objetivo: discutir resultados alcançados em intervenções e estudos realizados, para subsidiar ações de vigilância em saúde do trabalhador (Visat) da pesca. Métodos: foram referidos e discutidos estudos qualitativos e quantitativos desenvolvidos a partir de pesquisa participativa de base comunitária. Resultados: os estudos e intervenções revelaram as condições de trabalho e os riscos ocupacionais dessa atividade, sobretudo a exposição excessiva a movimentos repetitivos, e possibilitaram a quantificação da prevalência das lesões por esforço repetitivo e distúrbio osteomuscular relacionado ao trabalho (LER/Dort). Também contribuíram para analisar a qualidade de vida desses trabalhadores, a organização dos serviços de diagnóstico, a adaptação de protocolo clínico de LER/Dort e a capacitação das Equipes da Estratégia Saúde da Família atuantes em territórios pesqueiros. Conclusão: os estudos e as intervenções indicaram a possibilidade de reprodutibilidade desta experiência no âmbito da Visat no SUS.

Palavras-chave: LER/Dort; qualidade de vida; vigilância em saúde do trabalhador; vigilância ambiental; pesca.

\section{Abstract}

Introduction: fishermen are one of the largest and most traditional categories of workers in the world. In order to address the knowledge gaps in health problems related to this activity, and to develop actions together with the Unified Health System (SUS), in 2006 a set of studies and activities aimed at artisanal fishermen and shellfish gatherers was initiated, involving 13 municipal districts in Baía de Todos os Santos, Bahia, Brazil. Objective: to discuss results achieved in interventions and studies carried out with the purpose of subsidizing actions concerning fishermen's occupational health surveillance (Visat). Methods: we discuss and refer to qualitative and quantitative studies developed through community-based participatory research. Results: studies and interventions revealed artisanal fishermen's working conditions and occupational risks, especially those related to repetitive movements leading to high RSI/RMSDs prevalence. The results also contributed to the analysis of the workers' quality of life, organization of diagnostic services, adaptation of the RSI/WRMSDs clinical protocol, and training the Family Health Strategy Teams operating in fishing territories. Conclusion: the studies and interventions indicate the possibility of reproducing this experience within the framework of Visat at SUS.

Keywords: RSI/RMSDs; quality of life; occupational health surveillance; environmental monitoring; fishing. 


\section{Introdução}

A pesca artesanal (PA), também denominada "pesca em pequena escala", contribui enormemente na redução da pobreza, sustentabilidade ambiental e segurança alimentar de milhares de famílias em todo o mundo, especialmente nos países em desenvolvimento ${ }^{1}$. Os pescadores são uma das maiores e mais tradicionais categorias de trabalhadores no mundo, representando, em 2014, aproximadamente 38 milhões de pessoas, das quais 90\% se dedicam a essa atividade em tempo integral ou parcial ${ }^{1}$. Deste total, $84 \%$ encontram-se na Ásia, $10 \%$ na África, e $4 \%$ na América Latina e Caribe (ALC) ${ }^{1}$. O Brasil ocupa o quarto lugar na produção de pescado na ALC $^{1}$, em 2011 cerca de 1 a cada 200 brasileiros era pescador artesanal ${ }^{2}$. Dos aproximadamente $970 \mathrm{mil}$ pescadores registrados no Brasil até setembro de 2011, 957 mil (98\%) eram artesanais, que se organizavam em cerca de 760 associações, 137 sindicatos e 47 cooperativas $^{2}$. Entretanto, o conhecimento sobre condições de saúde e trabalho do pescador e de suas famílias, em especial de mulheres pescadoras, ainda é muito escasso ${ }^{3}$.

O termo "pesca artesanal" tende a caracterizar um empreendimento simples, de baixa tecnologia, realizado de forma individual (independente) ou familiar (em oposição a uma empresa industrial), organizado mais frequentemente pelo proprietário (mesmo que os barcos pertençam ao próprio pescador ou a algum investidor externo), com apoio da família. A PA pode ser de subsistência ou comercial, e também pode ser denominada "pesca em pequena escala", que por sua vez se refere ao subsetor de pesca comercial, sem embarcações e/ou com barcos de até 20 metros de comprimento. Neste relato, utilizaremos PA e pesca em pequena escala como sinônimos ${ }^{4}$.

O crescimento da oferta global de peixes aumentou nas últimas cinco décadas, bem como o consumo mundial per capita, que passou da média de 9,9 kg na década de 1960 para 19,7 kg em $2013^{1}$. Grande parte do peixe consumido no mundo vem da PA, que contribui com cerca de metade das capturas globais, cuja maioria se dirige ao consumo humano, sendo, portanto, muito importante para a segurança alimentar. Além disso, a PA emprega mais de $90 \%$ dos pescadores de captura do mundo, cuja metade são mulheres. Além de gerar emprego de tempo integral ou parcial, essa atividade fornece subsistência para milhões de pessoas que trabalham como autônomas para o sustento próprio e de suas famílias ${ }^{5}$.

Estima-se que 98\% de todos os pescadores e piscicultores vivem nos países em desenvolvimento da Ásia, África e América Latina. Juntos, eles capturam mais da metade dos peixes marinhos consumidos anualmente no mundo e a maioria dos consumidos nos países em desenvolvimento ${ }^{6}$. Mulheres representam cerca de $47 \%$ desses trabalhadores, correspondendo a 56 milhões de empregos ao longo de toda a cadeia de abastecimento, principalmente em atividades pós-colheita, como transformação e comercialização ${ }^{3,7}$. O trabalho das mulheres é considerado muitas vezes uma extensão do trabalho doméstico e, portanto, elas são ignoradas na coleta de dados oficiais sobre o trabalho não remunerado, fato que se torna uma barreira para acessar recursos financeiros e apoio institucional e político ${ }^{1}$. Outros dados relevantes sobre a importância da pesca em pequena escala podem ser verificados no Quadro 1.

Em 2011, foi produzido no Brasil 1,24 milhão de toneladas de pescado, e $45 \%$ dessa produção vem da $\mathrm{PA}^{2}$. Em 2011, o Nordeste liderou a produção, contribuindo com $34 \%$ (415,723 toneladas) da produção nacional de pescado, sendo $75 \%$ da $\mathrm{PA}^{2}$.

Apesar da alta participação na produção do pescado, as comunidades pesqueiras estão entre os grupos mais pobres da população. Estima-se que 5,8 milhões de pescadores no mundo ganham menos de US\$ 1 por dia, segundo dados de 2012 do World Bank ${ }^{7}$. A vulnerabilidade associada à pobreza pode se relacionar a problemas de saúde e acesso a serviços de saúde e educação, assim como conflitos com setores mais desenvolvidos, como turismo, aquicultura, agricultura, indústria, energia e infraestrutura ${ }^{8}$.

A Baía de Todos os Santos (BTS) é considerada a maior baía do Brasil, abrangendo 13 municípios do estado da Bahia, com área de estimada em $800 \mathrm{~km}^{2}$, sendo transformada em área de proteção ambiental, de acordo com a Lei Estadual $n^{0}$ 7.595/1999 ${ }^{9}$. As comunidades da região que sobrevivem da pesca de crustáceos e mariscos percebem a redução gradativa desses organismos e, consequentemente, de sua fonte de renda e aporte alimentar, e vêm lutando para manter o meio ambiente de seu trabalho saudável ${ }^{10,11}$. O conhecimento sobre sustentabilidade da PA, condições de saúde e de trabalho do pescador e sua família ainda é pouco relatado em estudos da saúde do trabalhador, nas suas diversas abordagens qualitativas e epidemiológicas. Ressalta-se ainda a precariedade dos serviços de saúde nas comunidades de pescadores, gerando graves consequências na morbidade e mortalidade dessa população, além da inexistência de ações estruturadas e permanentes da vigilância em saúde do trabalhador (Visat) voltadas para essa categoria $^{12}$, preocupação compartilhada em âmbito internacional $^{3}$. 
Quadro 1 Principais conclusões de relatório do Banco Mundial sobre a importância da PA no mundo

- Aproximadamente 120 milhões de trabalhadores em tempo integral e em tempo parcial são diretamente dependentes de cadeias de pesca de captura comercial como meio de subsistência.

- 97\% (116 milhões) dessas pessoas vivem em países em desenvolvimento. Entre eles:

- mais de 90\% (incluindo quase 32 milhões de pescadores) trabalham no subsetor de pesca em pequena escala;

- 47\% da força de trabalho total é composta de mulheres, que nos países em desenvolvimento equivale a 56 milhões de empregos;

- mais de metade (60 milhões) dos empregados nas cadeias de valor das pescarias nos países em desenvolvimento trabalham em pequena escala nas áreas de pesca continental;

- 73\% (cerca de 23 milhões) dos pescadores de países em desenvolvimento e dos trabalhadores da pesca vivem na Ásia.

- Mais de metade das capturas nos países em desenvolvimento é produzida pelo subsetor de pequena escala, e $90 \%$ a $95 \%$ dos desembarques em pequena escala destinam-se ao consumo humano local.

- As pescarias de captura comercial, incluindo atividades pós-colheita, são estimadas de forma conservadora, contribuindo com US\$ 274 bilhões para o PIB global em 2007. Este valor é um pouco menos de 1\% do PIB global total.

- A cadeia de valor de pré-colheita (incluindo atividades como construção de barcos e fabricação e venda de equipamentos) pode adicionar mais US\$ 160 bilhões para a estimativa do PIB.

- Estima-se que 5,8 milhões de pescadores no mundo ganhem menos de US\$ 1 por dia.

- O peixe é uma fonte vital de nutrição e alimenta mais de um bilhão de consumidores, para quem o peixe é um componente essencial na dieta.

- As pescarias de subsistência são uma grande atividade econômica e componente das comunidades rurais, mas os números de pescadores de subsistência a nível global e a importância desta atividade para essas famílias são pouco quantificados.

- O papel das mulheres na pesca não se limita ao processamento e à comercialização. As mulheres também são investidores, fontes de crédito, gerentes de receitas domésticas de pesca e tomam decisões importantes sobre nutrição familiar.

- As pescarias em larga escala capturam mais peixes, mas as pescarias de pequena escala produzem mais peixes para consumo doméstico.

- As estatísticas nacionais de produção de pesca parecem subestimar as capturas comerciais globais em cerca de $10 \%$ e capturas do interior de pequena escala em até $70 \%$.

- O emprego na pesca em pequena escala é várias vezes maior por tonelada de colheita do que em pescarias em grande escala.

- A pesca em pequena escala gera menos desperdício sob a forma de descarte (captura indesejada despejada no mar).

- Como outros setores de produção primária, as pescarias tendem a ser mais importantes nas economias em desenvolvimento do que economias desenvolvidas.

Fonte: World Bank ${ }^{7}$.

Para reduzir as lacunas do conhecimento, dar maior visibilidade aos problemas de saúde dessa categoria ocupacional e desenvolver ações com o Sistema Único de Saúde (SUS), em 2006 foi iniciado um projeto de pesquisa-ação sobre saúde dos trabalhadores de mariscagem e PA, com demandas de mulheres marisqueiras das comunidades pesqueiras da BTS. Elas se queixavam de dores crônicas generalizadas, principalmente nas articulações, de causa desconhecida, mas que se repercutiam na qualidade de vida (QV) e geravam sofrimento no cotidiano do trabalho ${ }^{13}$.

Partiu-se de estudos sobre as condições de trabalho, com metodologias qualitativas etnográficas e ergonômicas para conhecer o trabalho e os riscos à saúde, resultados que posteriormente foram desdobrados em outros estudos e ações que integraram o Programa de Saúde, Ambiente e Sustentabilidade de Trabalhadores da Pesca. Os projetos vinculados a este programa têm buscado aprofundar aspectos relacionados ao ambiente e ao processo de trabalho ${ }^{10-13}$, agravos frequentes, como distúrbios musculoesqueléticos (DME), no Brasil conhecidos como lesões por esforços repetitivos (LER), e distúrbios osteomusculares relacionados ao trabalho (Dort) ${ }^{14,15}$ e também à $\mathrm{QV}^{16,17}$.

Esse programa desenvolve investigações partindo de demandas concretas de saúde e ambiente das comunidades, dentro da concepção de pesquisa participativa de base comunitária (PPBC) - em inglês, community-based participatory research (CBPR). As parcerias com instituições de saúde e organizações de trabalhadores da PA têm permitido o desenvolvimento de processos e práticas de prevenção, diagnóstico clínico e funcional, tratamento e reabilitação, relacionados a patologias que atingem pescadores artesanais e marisqueiras. Além destas, parcerias com secretarias estaduais e municipais de saúde de cidades da BTS também têm sido feitas, envolvendo capacitação de profissionais no reconhecimento de agravos da contaminação ambiental dos territórios pesqueiros e dos processos de trabalho na PA.

Assim, o presente trabalho tem por objetivo discutir a experiência e os resultados alcançados em estudos e intervenções no âmbito da saúde do trabalhador e ambiental com pescadores artesanais da BTS, indicando possibilidades de reprodutibilidade desta experiência no âmbito da Visat do SUS. 


\section{Métodos}

Um amplo programa de pesquisa denominado Saúde, Ambiente e Sustentabilidade de Trabalhadores da Pesca vem sendo desenvolvido desde 2010 por diversos docentes e pesquisadores do Programa de Pós-Graduação em Saúde, Ambiente e Trabalho, da Universidade Federal da Bahia (UFBA), visando aprofundar temas referentes à saúde do pescador e suas relações com o ambiente e o trabalho. As ações desse programa se baseiam nos princípios da PPBC para envolver de forma equitativa os membros da comunidade, representantes de organizações e pesquisadores em todos os aspectos do processo de investigação e intervenções ${ }^{18}$.

A PPBC permite utilizar diferentes métodos investigativos. Estratégias metodológicas qualitativas e quantitativas foram organizadas pelo conjunto de ações e pesquisas realizadas, destacando-se estudos qualitativos com abordagens etnográficas, análise ergonômica do trabalho, estudos clínicos para elaborar protocolos de doenças decorrentes da PA, estudos epidemiológicos, entre outros. Para elaborar o presente relato, foram consultados relatórios de projetos de pesquisa, livros e artigos relacionados ao programa mencionado, publicados de janeiro de 2010 até novembro de 2017, que descrevem os métodos empregados. Ressalta-se que todos os estudos desenvolvidos foram devidamente submetidos e aprovados pelo Comitê de Ética em Pesquisa (CEP) da Faculdade de Medicina da Bahia (UFBA).

\section{Resultados e discussão}

\section{Intervenções iniciais}

No início das ações, buscou-se conhecer o processo de trabalho na PA no Brasil e seus possíveis riscos. Tal condição emergiu da escassez de literatura sobre o tema, considerando que estudos sobre saúde de pescadores se concentravam quase exclusivamente em países desenvolvidos, apresentando profundas diferenças com a realidade dos países em desenvolvimento. Uma das primeiras dificuldades foi a conceituação da PA, cuja definição varia de um país para outro ${ }^{7}$. A PA é exercida por produtores autônomos, em regime de economia familiar ou individual, em embarcações pequenas a remo, a vela ou mesmo motorizadas, mas sem instrumentos de apoio à navegação. Proprietários dos seus instrumentos de trabalho, os pescadores geralmente participam de todas as etapas de produção, e a maioria tem acesso limitado aos serviços de saúde ${ }^{13}$.Caracterizam-se como trabalhadores artesanais, que conhecem e geralmente realizam todas as tarefas da produção de pescado e mariscos, com base na produção familiar, pautada em saberes tradicionais, com suporte de redes sociais e culturais locais e duráveis.

A produção de pescado é dividida primordialmente por gênero e idade e, frequentemente, envolve modos de solidariedade e cooperação com objetivos econômicos ${ }^{19}$. Nesse âmbito, tais processos artesanais são de natureza pré-industrial, com exposição a riscos e problemáticas de acesso aos serviços de saúde e previdência social. No trabalho do pescador artesanal, a mobilização da força de trabalho está nas famílias, que assumem as condições de produção e serviço ${ }^{13}$, compondo simultaneamente o processo de reprodução social. Na produção familiar, a solidariedade estrutura o processo de trabalho, presente nas relações fundantes de sexualidade, que governam a organização da família. Além disso, a gestão do trabalho na PA é de responsabilidade do próprio pescador ou da marisqueira, portanto, é uma autogestão. Assim, a compreensão sobre o processo saúde-doença e as decisões no âmbito da prevenção, procura por assistência médica ou por afastamento do trabalho para tratamento são de responsabilidade do próprio pescador.

Um dos primeiros aspectos das intervenções foi conhecer a demanda por saúde, centrada principalmente nas queixas generalizadas de dores articulares, possivelmente relacionadas com o trabalho e caracterizadas como risco grave à saúde por LER/Dort em pescadores artesanais/marisqueiras ${ }^{13}$. Verificou-se nos estudos ergonômicos que a frequência média de movimentos repetitivos nas atividades de extração de mariscos era equivalente às encontradas na atividade do digitador. No caso da cata de mariscos, são executados, em média, 10.200 movimentos repetitivos por hora, superior à norma oficial brasileira, que estabelece o limite de 8 mil toques por hora para a digitação. Além do esforço dos movimentos repetitivos, as pescadoras têm jornadas semanais de até 110 horas, durante longos anos, agravadas pela inserção no trabalho em idade precoce, geralmente na infância ${ }^{13}$.

Essas cadências nocivas exigiram a necessidade de entender os motivos para jornadas extenuantes e de aceleração de movimentos repetitivos, certamente bem diferentes do trabalhado assalariado. Durante a coleta do marisco, a própria marisqueira faz a gestão do trabalho, mantendo o controle do seu tempo de trabalho e das pausas. Mas as dificuldades financeiras, associadas ao desemprego no setor formal, impõem condições e ritmo de trabalho a quem busca sobreviver, seja da venda do marisco, seja do seu consumo próprio e da família. A demanda do trabalho é determinada pelo mercado de mariscos, exploração do intermediário e consumo do produto. 
A dificuldade de armazenar produtos de pesca em câmaras frigoríficas ou freezers exige a venda do produto logo após a coleta. Esta é, portanto, uma atividade cotidiana, sem descanso semanal, e o afastamento do trabalho só ocorre con impedimento por condições climáticas, como períodos de chuva ou em situações de adoecimento e/ou parto. A necessidade de sobreviver impede pausas nas jornadas de trabalho, mesmo com autogestão, agravando riscos ergonômicos para LER/Dort. Essas baixas condições implicam a necessidade de ritmos excessivos, com cadências infernais de trabalho ${ }^{13}$.

Diante dessas observações, conclui-se que marisqueiras e pescadores artesanais atendem aos parâmetros de riscos ergonômicos de LER/Dort, como excesso de movimentos repetitivos; de tempo de trabalho; sobrecarga de atividades nos membros superiores; ausência de pausas; e cadências aceleradas decorrentes da miséria social. Tais estudos foram essenciais para caracterizar o nexo clínico, com riscos no trabalho, e para diagnosticar doenças do trabalho no ambulatório do Serviço de Segurança e Saúde Ocupacional (Sesao) do Hospital Universitário Professor Edgard Santos (Hupes) e respectivos encaminhamentos previdenciários para situações graves, de incapacidade para o trabalho. Mais ainda, permitiram a triangulação com estudos epidemiológicos realizados posteriormente.

Como resultado dos primeiros estudos, elaboraram-se intervenções na atenção à saúde e um curso de capacitação para as equipes da Estratégia Saúde da Família (ESF), que contaram com associações de pescadoras artesanais/marisqueiras em todo o processo. O curso teve caráter eminentemente prático e utilizou como principal material didático uma cartilha, elaborada com as pescadoras artesanais.

Os casos suspeitos de LER/Dort identificados nas ESF eram encaminhados para o ambulatório especializado do Sesao, onde foram elaborados protocolos clínicos para investigar LER/Dort direcionados aos profissionais da PA. De 2005 a 2013, 873 pescadores foram atendidos no Sesao e, ao serem diagnosticados com LER/Dort, eram encaminhados para o Instituto Nacional de Seguridade Social (INSS) com seus relatórios clínicos. Em recente análise de 39 casos confirmados clinicamente de LER/Dort encaminhados do Sesao para INSS, identificaram-se: síndrome do manguito rotador (59\%), síndrome do túnel do carpo (49\%), tendinite bicipital (18\%), espondiloartrose lombar (15\%), espondiloartrose da coluna cervical (13\%), síndrome de Quervain (10\%) e bursite do ombro (10\%) (dados não publicados). Essa casuística ambulatorial é a única no país para esses trabalhadores e, com isso, foram elaborados protocolos clínicos para estabelecer o nexo entre trabalho e LER/Dort, adaptado para as atividades na PA.

\section{Estudos epidemiológicos}

Apesar da importante casuística obtida no Sesao, era necessário dimensionar o quadro epidemiológico de LER/Dort nessa categoria. Diante da escassez na literatura sobre saúde de pescadores no Brasil $^{20}$, a equipe iniciou uma série de estudos epidemiológicos envolvendo PA na BTS. Os resultados dos estudos qualitativos foram fundamentais para maior compreensão do processo de trabalho, o que permitiu melhor adequação dos instrumentos validados e condução da pesquisa epidemiológica. Os primeiros estudos epidemiológicos no município de Saubara (BA) envolvendo uma amostra de 209 pescadoras artesanais/marisqueiras ${ }^{14,15}$, em 2013, foram originais e de extrema relevância, pois até aquele momento não existiam estudos desse tipo na literatura científica nacional.

Müller e colaboradores ${ }^{16}$, usando instrumentos quantitativos validados, autorizados e transculturados para o Brasil, evidenciaram alta prevalência (94,7\%) de LER/Dort global em todas as regiões do corpo, assim como hipertensão arterial $(27,3 \%)$, artrite (10,5\%) e diabetes (6,7\%). Com os resultados, mensurou-se a presença desses agravos com a qualidade de vida relacionada à saúde (QVRS) de pescadoras artesanais/marisqueiras brasileiras.

Falcão e colaboradores ${ }^{14}$ demonstraram a prevalência elevada de LER/Dort no pescoço, ombro e membros superiores distais em pescadoras artesanais/marisqueiras, e ainda ratificaram que quase todas as marisqueiras alegaram dor ou desconforto em alguma parte do corpo no último ano. Quando aplicado o critério para classificação de severidade (maior ou igual a 3 em uma escala de 0 a 5), apenas $2,9 \%(\mathrm{n}=6)$ das trabalhadoras que manifestavam sintomas não apresentaram LER/Dort, revelando a importância dessa patologia dolorosa para a população de marisqueiras em Saubara.

Outro estudo de Falcão e colaboradores ${ }^{15}$ revelou que as LER/Dort no pescoço ou no ombro se associavam com as demandas físicas referentes ao trabalho, principalmente à coleta do marisco, que obriga a marisqueira a se apoiar sobre o cotovelo e sobre o punho, tronco rodado, com movimentos precisos e muito finos com as mãos, como empurrar e puxar a carga. Casos de LER/Dort em membros superiores distais foram associados com a atividade de cata (separação do marisco da concha, com o tronco inclinado para a frente, pressão física com as mãos sobre a ferramenta, força muscular nos braços ou mãos, para puxar e levantar a carga). As marisqueiras que variavam mais as posturas, o manuseio de carga, a força muscular e a pressão física apresentaram menos LER/Dort nas duas unidades funcionais relatadas. 
Na análise da QV com o uso do Medical outcomes study 36-item short-form healthy survey (SF-36 v1), os achados obtidos para a população de pescadoras artesanais apontam o pior status de saúde na população de 45 anos ou mais, com quatro anos ou menos de estudo, e a presença de doenças crônicas não transmissíveis, em especial LER/Dort, hipertensão arterial e artrite ${ }^{16}$. Ressalta-se ainda que elas apresentaram QVRS nos oito domínios estudados, com índice muito menor se comparado com a encontrada na população brasileira de referência na época estudada ${ }^{16}$.

Nessa trajetória, percebeu-se a necessidade de avaliar a funcionalidade do membro superior e correlacioná-lo com a QV de pescadoras artesanais/ marisqueiras para confirmar o agravo de saúde e sua repercussão na vida cotidiana e no trabalho. Estudo realizado por Müller e colaboradores ${ }^{17}$ demonstrou que a presença de LER/Dort nos membros superiores aumenta os escores médios do instrumento disabilities of the arm, shoulder and hand (Dash), atestando que o acometimento patológico crônico aumenta a incapacidade (disfunção moderada) dos membros superiores das pescadoras artesanais.

Assim, vislumbra-se uma condição grave, pois em vista da informalidade dessa atividade de trabalho, tornam-se muito complexas a garantia dos direitos previdenciários e a atenção à saúde, necessárias nessas condições. Note-se, entretanto, que apenas a identificação de uma condição clínica não prediz com acurácia os cuidados necessários, o desempenho no trabalho, os benefícios sociais e a integração social. Desse modo, o trabalho de pescadoras artesanais/marisqueiras deve ser observado com muito mais atenção, principalmente pelos poderes públicos.

Para Müller e colaboradores ${ }^{17}$, a discussão sobre incapacidade e perda da funcionalidade dos membros superiores das pescadoras artesanais/marisqueiras ratifica a necessidade de ações de promoção, prevenção e manutenção das condições de saúde dessa categoria profissional. É notório que a presença de doenças crônicas e a ausência de intervenções que possibilitem a reabilitação desses profissionais geram, em longo prazo, casos de incapacidade permanente, que inviabilizam a subsistência das comunidades tradicionais.

As patologias constatadas representam também um grave problema socioeconômico para essas profissionais, pois a manutenção da saúde é imprescindível para a execução do trabalho que gera subsistência familiar. Dessa forma, considerando-se o alto grau dos riscos dessa atividade e sua natureza informal, as medidas de promoção e proteção à saúde precisam ser consideradas prioritárias no rol das políticas públicas de saúde e previdência social, permitindo a melhoria das condições de vida e saúde, a redução da pobreza e da desigualdade social dessa população. A ESF, nas áreas com predominância de comunidades pesqueiras, precisa ampliar a cobertura e levar em conta as especificidades desse trabalho para poder assisti-la e prevenir enfermidades. Toda esta discussão foi levada para as capacitações das ESF.

A interferência das condições de saúde decorrentes de patologias associadas ao trabalho limita/incapacita diretamente a QV do pescador artesanal. Os estudos mencionados evidenciam tal problemática e reforçam a hipótese de que pescadoras artesanais/ marisqueiras estão entre as categorias profissionais do país com maior prevalência de LER/Dort, apesar de continuarem sem acesso ao diagnóstico e à prevenção dessas enfermidades.

\section{A vigilância nos territórios de pesca na BTS}

A poluição pela falta de saneamento básico é agravada pelo turismo predatório e pela contaminação química ocasionada pela indústria e pelo agronegócio, que atingem há anos a BTS ${ }^{21}$. Carvalho e colaboradores ${ }^{11}$ encontraram várias evidências de que a região vem sendo gradativamente comprometida por poluentes orgânicos e industriais que diminuem a biodiversidade marinha e, consequentemente, reduzem as espécies deste ecossistema ${ }^{21}$. Essas condições ambientais e de trabalho, que afetam a saúde do trabalhador, em especial o da pesca, motivaram a elaboração de um projeto que abordasse o problema na perspectiva da vigilância em saúde ambiental e da saúde do trabalhador no SUS.

Este projeto buscou: identificar situações de riscos e agravos dessas populações; elaborar e implementar protocolos de atenção integral à saúde com foco nas especificidades da categoria, que em algumas situações resultou em encaminhamento para ações com a previdência social; elaborar processos organizacionais para implementar ações intersetoriais e na rede de saúde, partindo da ESF; priorizou a participação da categoria da pesca em todo o processo desde a identificação do problema às intervenções. Este projeto tomou por base o modelo proposto por Machado e colaboradores ${ }^{22}$, abrangendo ações internas e externas ao SUS.

A Visat e a vigilância em saúde ambiental (Visam), na pesca de pequena escala, estão no contexto da vigilância em saúde, uma prática sanitária orientada essencialmente para gerar e analisar a informação sobre problemas de saúde relevantes ou prioritários para executar ações que promovam a saúde, mapeiem e previnam riscos, detectem agravos precocemente e assistam casos de prevenção a sequelas e óbitos ${ }^{22}$. 
A Visat especifica a informação sobre o processo saúde-doença/atenção para ação dirigida aos processos de trabalho, na perspectiva de propiciar práticas de controle e/ou eliminação de riscos, detecção precoce de doenças do trabalho relacionadas à PA, realização de projetos terapêuticos que contemplem direitos à saúde e à previdência social, incluindo a assistência adequada para prevenção de incapacidades e reinserção profissional ${ }^{22}$. Não é possível ação de VISAT sem a participação das organizações sociais de trabalhadores envolvidas na discussão do processo de trabalho e nas mudanças necessárias à melhoria das condições de vida e de trabalho.

Com base em tais conceitos, os pescadores artesanais e as marisqueiras são sujeitos sociais centrais das práticas sanitárias e dos processos de melhoria das condições de trabalho e saúde nos territórios pesqueiros. As ações de saúde no âmbito da Visat para essa população se ampliam para a esfera previdenciária, pois, como trabalhadores autônomos, eles têm direito previdenciário ao seguro de acidente de trabalho (SAT), semelhante ao trabalhador assalariado, sendo protegidos pelo regime formal da Consolidação das Leis do Trabalho (CLT) ${ }^{22}$.

A inclusão da questão previdenciária é importante porque, frequentemente, o direito ao seguro acidentário aos pescadores é negado, pela ausência de serviços de saúde do SUS em condições de reconhecer doenças e acidentes do trabalho, caracterizar incapacidades, notificar e emitir a comunicação de acidente do trabalho (CAT), conforme o caso, ou encaminhar à perícia médica todos os incidentes relacionados a esse conjunto de direitos.

Nega-se, por decorrência, o direito aos benefícios essenciais para tratar as enfermidades e para o retorno ao trabalho. Nessa perspectiva, as intervenções devem envolver, simultaneamente, direitos ao tratamento da saúde por meio do SUS, à previdência social e ao trabalho digno. Adiciona-se à questão ocupacional a grave problemática dos riscos de acidentes e da contaminação ambiental que atingem territórios de pesca, sendo o exemplo mais recente a catástrofe em Mariana, Minas Gerais, considerado um crime sócio-ocupacional-ambiental ${ }^{23}$.

Fundamental ainda é compreender a relação entre os processos produtivos que ocorrem nos territórios, suas relações com o ambiente e a saúde das pessoas. Conforme apontam Dias e colaboradores ${ }^{24}$, é preciso inserir as ações de vigilância nas práticas cotidianas das equipes da ESF, pois os profissionais necessitam desenvolver ações intra e intersetoriais, além das habilidades de planejamento, organizando ações de atenção à demanda espontânea, visando mudar a QV das pessoas do território onde atuam.
Experiências vivenciadas com pescadores artesanais da BTS, que podem ser consultadas com detalhes em $\operatorname{artigos}^{10-17}$ e em livro ${ }^{25}$, têm apontado que este é um caminho possível.

\section{Considerações finais}

Os resultados das pesquisas vêm subsidiando ações e proposições de políticas ambientais e de saúde com o SUS, na implantação de uma rede de atenção à saúde do pescador artesanal. Essa produção científica é fundamental para reconhecer, junto à previdência social, o nexo causal entre condições de trabalho e doenças e acidentes do trabalho, objetivando-se conquistar direitos previdenciários, aplicar medidas preventivas e melhorar as condições laborais dessa categoria ocupacional.

Os pescadores artesanais representam uma categoria milenar, de grande escala no mundo todo, porém não têm acesso aos serviços de saúde do trabalhador e às respectivas ações de Visat. É necessário, assim, construir o direito à saúde do trabalhador da PA, compondo-se com o direito ambiental e direito à previdência social. No conjunto de estudos e intervenções realizadas, evidenciaram-se experiências de intervenções no âmbito da saúde do trabalhador e ambiental que podem subsidiar políticas de Visat nos diversos territórios pesqueiros no Brasil.

Os estudos apresentaram diversas estratégias participativas de pesquisa e intervenções com os pescadores artesanais, propiciando: conhecimento das condições de trabalho; caracterização da exposição a diversos riscos ambientais; caracterização do risco decorrente da organização do trabalho na pesca, gerando risco grave à saúde por esforços repetitivos; organização de serviços qualificados de diagnóstico de doenças do trabalho para compreender suas especificidades na PA; elaboração de protocolo sobre LER/Dort adaptado ao trabalho artesanal; construção de casuística única no país para trabalhadores artesanais portadores de LER/Dort; caracterização da articulação dos riscos ocupacionais com riscos ambientais; quantificação da dimensão epidemiológica do problema, que mostra as pescadoras artesanais e marisqueiras como vítimas de alta prevalência de LER/Dort em relação a outros trabalhadores; identificação de comprometimento da QV em decorrência de patologias relacionadas ao trabalho; realização de ações de educação em saúde com profissionais da ESF atuantes em territórios pesqueiros; produção de material educativo como cartilhas, manuais e vídeos sobre condições de trabalho; e elaboração de modelo de intervenção, projetos de pesquisa e intervenções na área de saúde do trabalhador, ambiente e sustentabilidade da PA na BTS. 
Enfatiza-se que, antes dos estudos comentados, não havia na literatura referências sobre LER/ Dort em pescadores artesanais do Brasil. Com isso, espera-se que os estudos e as experiências de intervenções referidas neste relato contribuam com a necessária construção de ações de Visat, iniciando uma fase de debates sobre a consequentialist epide${ }_{m i o l o g}{ }^{26}$ na área da saúde dos trabalhadores artesanais da pesca no Brasil e em países da América Latina, África e Ásia.

\section{Contribuição dos autores}

Todos os autores contribuíram igualmente no levantamento e na interpretação das informações, na elaboração do manuscrito e na aprovação da versão final publicada.

\section{Referências}

1. FAO. The state of world fisheries and aquaculture 2016: contributing to food security and nutrition for all. Rome: FAO; 2016 [citado 4 nov 2017]: [200 p.]. Disponível em: www.fao.org/3/a-i5555e.pdf

2. Brasil. Ministério da Pesca e Aquicultura. Boletim estatístico da pesca e aquicultura. Brasília, DF: MPA; fev 2012 [citado 25 jan 2018]: [129 p.]. Disponível em: http://sinpesq.mpa.gov.br/preps cms/download/boletim_2010/boletim_estatistico_ mpa_2010.pdf

3. FAO. Towards gender-equitable small-scale fisheries governance and development. Rome: FAO; 2017 [citado 29 out 2018]: [174 p.]. Disponível em: www.fao.org/3/a-i7419e.pdf

4. FAO. Fisheries and Aquaculture Department. Fisheries. Rome: FAO; 2014 [citado 20 nov 2017]. Disponível em: http://www.fao.org/faoterm/ collection/fisheries/en/

5. FAO. Voluntary guidelines for securing sustainable small-scale fisheries in the context of food security and poverty eradication. Rome: FAO; 2015 [citado 29 out 2018]: [18 p.]. Disponível em: http://www. fao.org/3/a-i4356e.pdf

6. Berkes F. Alternatives to conventional management: lessons from small-scale fisheries. Environments. 2003;31(1):5-19.

7. World Bank. Hidden harvest. The global contribution of capture fisheries. Washington, DF: World Bank; 2012 [citado 19 nov 2017]. Disponível em: https://openknowledge. worldbank.org/bitstream/handle/10986/11873 /664690ESWOP1210120HiddenHarvest0web. pdf? sequence $=1$ \&isAllowed $=\mathrm{y}$

8. FAO. Committee on Fisheries. Good practices in the governance of small-scale fisheries: sharing of experiences and lessons learned in responsible fisheries for social and economic development. Roma: FAO; 2011. $29^{\circ}$ sessão, 31 jan/4 fev.

9. Brasil. Presidência da República. Decreto n ${ }^{0} 7.595$, de 5 de junho de 1999. Cria a Área de Proteção Ambiental - APA da Baía de Todos os Santos e dá outras providências.
10. Sales IG, Rêgo RF, Pena PGL. Direito ambiental do trabalho e o meio ambiente de trabalho saudável In: Atanaka-Santos M, Pignatti MG, Chaves AL, organizadores. Questões ambientais em saúde coletiva. Cuiabá: UFMT; 2012. p. 96-118.

11. Carvalho IG, Rêgo RC, Larrea-Killinger C, et al. Towards a dialogue of knowledge between subsistence fishermen, shellfish gatherers and environmental labor law. Cien Saúde Colet. 2014;19(10):4011-22.

12. Pena PGL, Martins V, Rêgo RF. Por uma política para a saúde do trabalhador não assalariado: o caso dos pescadores artesanais e das marisqueiras. Rev Bras Saúde Ocup. 2013;38(127):57-68.

13. Pena PG, Freitas MC, Cardim A. Non-industrial labor, internal conditions and repetitive strain injury: a case study in a shellfish-rearing community on Mare Island, State of Bahia, Brazil. Cien Saúde Colet. 2011;16(8):3383-92.

14. Falcao IR, Couto MCB, Lima VM, et al. Prevalence of neck and upper limb musculoskeletal disorders in artisan fisherwomen/shellfish gatherers in Saubara, Bahia, Brazil. Cien Saúde Colet. 2015;20(8):2469-80.

15. Falcão IR, Rêgo RF, Couto MCBM, et al. Fatores associados com os distúrbios musculoesqueléticos em pescadoras artesanais/ marisqueiras em Saubara, Bahia, Brasil. Cien Saúde Colet [internet]. Out 2017 [citado 28 jan 2018]. Disponível em: http://www.cienciaesaudecoletiva. com.br/artigos/fatores-associados-com-osdisturbios-musculoesqueleticos-em-pescadorasartesanaismarisqueiras-em-saubara-bahiabrasil/16443

16. Müller JS, Falcao IR, Couto M, et al. Health-related quality of life among artisanal fisherwomen/ shellfish gatherers: lower than the general population. Int J Environ Res Public Health. 2016;13(5):1-12.

17. Müller JS, Falcao IR, Couto M, et al. Artisanal fisherwomen/shellfish gatherers: analyzing the impact of upper limb functioning and disability on health-related quality of life. Cien Saúde Colet. 2017;22(11):3635-44. 
18. Cook WK. Integrating research and action: a systematic review of community-based participatory research to address health disparities in environmental and occupational health in the USA. J Epidemiol Community Health. 2008;62(8):668-76.

19. Pena PG, Gomez CM. Health of subsistence fishermen and challenges for occupational health surveillance. Cien Saúde Colet. 2014;19(12):4689-98.

20. Rios AO, Rêgo RF, Pena PGL. Doenças em trabalhadores da pesca. Rev Baiana Saúde Púb. 2011 jan-mar;35(1):175-88.

21. Hatje V, Andrade JB. Baía de Todos os Santos: aspectos oceanográficos. Salvador: EDUFBA; 2009 [citado 19 nov 2017]: [306 p.]. Disponível em: http://www.repositorio.ufba.br/ri/handle/ $\mathrm{ufba} / 18$
22. Machado JMH, Villardi JWR, Franco Netto G, et al. Vigilância em saúde ambiental e do trabalhador: reflexões e perspectivas. Cad Saúde Colet. 2011;19(4):399-406.

23. Lacaz FAC, Porto MFS, Pinheiro TM. Tragédias brasileiras contemporâneas: o caso do rompimento da barragem de rejeitos de Fundão/Samarco. Rev Bras Saúde Ocup. 2017;42:e9.

24. Dias EC, Silva TLS, Almeida, MHC. Desafios para a construção cotidiana da vigilância em saúde ambiental e em saúde do trabalhador na atenção primária à saúde. Cad Saúde Colet. 2012;20(1):15-24.

25. Pena PGL, Martins VLA. Sofrimento negligenciado: doenças do trabalho em marisqueiras e pescadores artesanais. Salvador: EDUFBA; 2014. 352 p.

26. Galea S. An argument for a consequentialist epidemiology. Am J Epidemiol. 2013;178(8):1185-91. 